\title{
HUBUNGAN KEDALAMAN SUMUR BOR DENGAN KADAR BESI (Fe) DAN MANGAN (Mn) DI KELURAHAN MALENDENG KECAMATAN PAAL 2 KOTA MANADO
}

\author{
Amina Misa ${ }^{1}$, Risman S. Duka $^{2}$, Semuel Layuk ${ }^{3}$, Yozua T. Kawatu ${ }^{4}$ \\ ${ }^{1)}$ Dinas Kesehatan Kabupaten Kepulauan Talaud \\ ${ }^{2)}$ Jurusan Kesehatan Lingkungan Poltekkes Kemenkes Manado \\ Email : amina.misa@yahoo.com
}

\begin{abstract}
Water is one of the basic human needs so it is very important to monitor water quality. Groundwater often contains Iron (Fe) and Manganese (Mn) which exceeds the maximum permissible level, the content of Iron (Fe) and Manganese (Mn) in water causes the color of the water to turn yellow-brown after a while of contact with air. This study aims to determine the relationship between the depth of drill wells with iron (Fe) and manganese (Mn) levels in Malendeng Sub-District, Paal 2 Manado District. The research method used was observational analytic with study design cross sectional using statistical test Chi-Square. The sample in this study amounted to 33 bore wells. The independent variable studied was the depth of the wellbore. The results of this study indicate that for a depth of $<20$ meter borehole there are 12, drill wells $>20$ meters there are 21. Iron ( $\mathrm{Fe})$ levels do not meet the 3\% requirement and Manganese ( $\mathrm{Mn}$ ) that does not meet the requirements of 39\%.test results Chi Square show the depth of the bore well with Iron (Fe) $p=1,000$. for the depth of the bore well with Manganese content $(\mathrm{Mn}) p=0.465$, Ho is accepted, meaning that there is no significant relationship between the depth of the bore well with the levels of Iron (Fe) and Manganese (Mn) in Malendeng Sub-District, Paal 2 Manado. It is hoped that the public will pay more attention to water conditions that meet health requirements.
\end{abstract}

Keywords: Drilling Well, Iron (Fe) and Manganese (Mn) Levels

\begin{abstract}
Abstrak. Air merupakan salah satu kebutuhan pokok manusia sehingga sangat perlu dilaksanakan pengawasan kualitas air. Air tanah sering mengandung Zat Besi $(\mathrm{Fe})$ dan Mangan $(\mathrm{Mn})$ yang melebihi kadar maksimum yang diperbolehkan, adanya kandungan Besi (Fe) dan Mangan (Mn) dalam air menyebabkan warna air berubah menjadi kuning-kecoklatan setelah beberapa saat kontak dengan udara. Penelitian ini bertujuan untuk mengetahui Hubungan Kedalaman Sumur Bor dengan Kadar Besi (Fe) dan Mangan (Mn) di Kelurahan Malendeng Kecamatan Paal 2 Manado. Metode penelitian yang digunakan adalah analitik observasional dengan rancangan penelitian cross sectional menggunakan uji statistik Chi-Square. Sampel dalam penelitian ini berjumlah 33 sumur bor. Variabel bebas yang diteliti adalah kedalaman sumur bor. Hasil penelitian ini menunjukkan untuk kedalaman sumur bor $<20$ meter ada 12, sumur bor $>20$ meter ada 21. Kadar Besi (Fe) tidak memenuhi syarat 3\% dan Mangan (Mn) yang tidak memenuhi syarat 39\%. Hasil uji Chi Square menunjukkan untuk kedalaman sumur bor dengan kadar Besi (Fe) $p=1$ sedangkan untuk kedalaman sumur bor dengan kadar Mangan (Mn) p = 0,465 maka Ho diterima berarti tidak terdapat hubungan yang bermakna antara kedalaman sumur bor dengan kadar Besi (Fe) dan Mangan (Mn) di Kelurahan Malendeng Kecamatan Paal 2 Manado. Diharapkan agar masyarakat lebih memperhatikan kondisi air yang memenuhi syarat kesehatan.
\end{abstract}

Kata Kunci : Sumur Bor, Kadar Besi (Fe) dan Mangan (Mn).

Air merupakan salah satu sumber daya alam yang memiliki fungsi sangat penting bagi kelangsungan hidup manusia. Ditinjau dari sudut kesehatan masyarakat, kebutuhan air untuk Keperluan Higiene harus memenuhi syarat kualitas agar kesehatan masyarakat terjamin. Standar Baku Mutu Kesehatan Lingkungan untuk media Air untuk Keperluan Higiene Sanitasi meliputi parameter fisik, biologi, dan kimia yang dapat berupa parameter wajib dan parameter tambahan, air untuk Keperluan Higiene Sanitasi tersebut digunakan untuk pemeliharaan kebersihan perorangan seperti mandi dan sikat gigi, serta untuk keperluan cuci bahan pangan, peralatan makan, dan pakaian. Selain itu Air untuk Keperluan Higiene Sanitasi dapat digunakan sebagai air baku air minum, (Permenkes, 2017).

Standar kelayakan kebutuhan air bersih adalah 49,5 liter/kapita/hari. Badan dunia UNESCO sendiri pada tahun 2002 telah menetapkan hak dasar manusia atas air yaitu sebesar 60 1tr/org/hari. Direktorat Jenderal Cipta 
Karya Departemen Pekerjaan Umum membagi lagi standar kebutuhan air minum tersebut berdasarkan lokasi wilayah Pedesaan dengan kebutuhan 60 liter/per kapita/hari, Kota Kecil dengan kebutuhan 90 liter/per kapita/hari, Kota Sedang dengan kebutuhan 110 liter/per kapita/hari, Kota Besar dengan kebutuhan 130 liter/per kapita/hari, Kota Metropolitan dengan kebutuhan 150 liter/per kapita/hari (Permendagri, 2006 ).

Jenis sumber air untuk seluruh kebutuhan rumah tangga di Indonesia pada umumnya adalah sumur gali terlindung $(29,2 \%)$, sumur pompa $(24,1 \%)$, dan air ledeng/PDAM (19,7\%). Di Perkotaan lebih banyak rumah tangga yang menggunakan air dari sumur bor/pompa $(32,9 \%)$ dan air ledeng/PDAM (28,6\%), sedangkan di Pedesaan lebih banyak yang menggunakan sumur gali terlindung $(32,7 \%)$. Pada rumah tangga yang menggunakan sumber air untuk seluruh keperluan rumah tangga selain air sungai/danau/irigasi, pemakaian air per orang per hari oleh rumah tangga di Indonesia, pada umumnya berjumlah antara 50 sampai 99,9 liter (28,3\%), dan antara 100 sampai 300 liter (40\%), (Riskesdas, 2013).

Proporsi rumah tangga tertinggi untuk pemakaian air antara 100 liter sampai 300 liter per orang per hari paling tinggi adalah Banten $(54,5 \%)$, sedangkan proporsi terendah adalah Nusa Tenggara Timur $(10,1 \%)$. Masih terdapat rumah tangga dengan pemakaian air kurang dari 20 liter per orang per hari, bahkan kurang dari 7,5 liter per orang per hari (masing-masing 4,9 persen dan 0,1 persen). Berdasarkan provinsi, proporsi rumah tangga dengan jumlah pemakaian air per orang per hari kurang dari 20 liter tertinggi adalah Nusa Tenggara Timur $(30,4 \%)$ diikuti Papua $(22,5 \%)$, (Riskesdas, 2013).

Menurut karakteristik, proporsi rumah tangga dengan pemakaian air kurang dari 20 liter per orang per hari di Pedesaan lebih tinggi $(5,8 \%)$ dibandingkan di Perkotaan (4,0\%), sebaliknya proporsi rumah tangga jumlah pemakaian air per orang per hari 20 liter atau lebih di Perkotaan lebih tinggi 95,9\%) dibandingkan dengan di Pedesaan (94,2\%). Rumah tangga dengan kuintil indeks kepemilikan menengah sampai teratas cenderung menggunakan air lebih dari 100 liter per orang per hari, sedangkan rumah tangga dengan kuintil indeks kepemilikan menengah bawah dan terbawah kecenderungan pemakaian air kurang dari 20 liter per orang per hari, (Riskesdas, 2013).
Kadar Ferum (Fe) adalah metal berwarna putih keperakan, liat dan dapat dibentuk. Besi di alam didapat sebagai hematit. Keberadaan besi dalam air bersifat terlarut, menyebabkan air menjadi merah kekuning-kuningan, menimbulkan bau amis, dan membentuk lapisan seperti minyak, dan salah satu elemen yang dapat ditemui hampir pada setiap tempat di bumi, pada semua lapisan geologis dan semua badan air. Ion Fe atau besi selalu di jumpai pada air alami dengan kadar oksigen yang rendah, seperti pada air tanah dan pada daerah danau yang tanpa udara, (Munfiah dkk, 2013).

Mangan (Mn) adalah logam berwarna abuabu putih. berupa unsur reaktif yang mudah menggabungkan dengan ion dalam air dan udara. Di bumi, mangan ditemukan dalam sejumlah mineral kimia yang berbeda dengan sifat fisiknya, tetapi tidak pernah ditemukan sebagai logam bebas di alam. Mineral yang paling penting adalah pyrolusite, karena merupakan mineral bijih utama untuk mangan. Kehadiran mangan dalam air tanah bersamaan dengan besi yang berasal dari tanah dan bebatuan. Mangan dalam air berbentuk mangan bikarbonat $\left(\mathrm{Mn}\left(\mathrm{HCO}_{3}\right)_{2}\right.$, mangan klorida $\left(\mathrm{MnCl}_{2}\right)$ dan mangan sulfat $\left(\mathrm{MnSO}_{4}\right)_{3}$, (Setiyono, 2014).

Adanya kandungan Besi (Fe) dan Mangan (Mn) dalam air menyebabkan warna air tersebut berubah menjadi kuning-coklat setelah beberapa saat kontak dengan udara. Disamping menimbulkan gangguan kesehatan juga menimbulkan bau yang kurang enak dan menyebabkan warna kuning pada dinding bak kamar mandi serta bercak-bercak kuning pada pakaian. Oleh karena itu, menurut Permenkes No 907 tahun 2002, kadar $\mathrm{Fe}$ dalam air minum maksimum yang diperbolehkan adalah $0,3 \mathrm{mg} / \mathrm{Lt}$ dan kadar Mn dalam air minum yang diperbolehkan adalah 0,1 mg/Lt, (Sari, 2014).

Sumur bor adalah salah satu jenis sumur buatan yang dibuat dengan bantuan alat bor untuk mencapai kedalaman sumur yang cukup sehingga akan bertemu dengan sumber air tanah yang melimpah. Suplai air pada dasarnya sangat melimpah karena sebagian besar bumi ini memiliki wilayah perairan yang lebih luas daripada daratan.

Hasil penelitian sebelumnya yang dilakukan oleh Mutiara Tahun 2014 bahwa air sumur bor di Kelurahan Malendeng masih dalam batas yang memenuhi syarat dengan rata-rata yaitu Kadar Besi (Fe) 0,03 mg/L, dan Kadar Mangan (Mn), 0,03 
mg/L. Ditinjau dari standar baku mutu air bersih pada PERMENKES RI No.416/MENKES/ PER/IX /1990 dengan persyaratan Maksimum Kadar Besi (Fe) 1,0 mg/L, dan Kadar Mangan (Mn) 0,5 mg/L.

Berdasarkan surfei awal yang dilakukan di Kelurahan Malendeng Kecamatan Paal 2 Manado pada umumnya masyarakat menggunakan air sumur bor sebagai sumber air bersih untuk keperluan sehari-hari seperti memasak, mencuci, mandi dan sebagainya. Jumlah kepala keluarga (KK) khususnya Lingkungan yang akan dijadikan sebagai tempat penelitian adalah 858 KK. Setiap Lingkungan memiliki sumur bor yaitu Lingkungan $\mathrm{IV}=24$ sumur bor, Lingkungan VI = 30 sumur bor, Lingkungan VII = 30 sumur bor, Lingkunga

\section{Metode}

Jenis penelitian yang digunakan adalah analitik observasional dengan rancangan croos sectional yaitu penelitian variable sebab dan akibat diukur atau dikumpulkan dalam waktu bersamaan. Populasi dalam penelitian ini adalah 189 sumur bor dan yang di jadikan sampel ada 33 sumur bor yang
VIII = 105 sumur bor, jumlah keseluruhan adalah 189 sumur bor. Dilihat dari hasil kualitas fisiknya air sumur bor yang digunakan oleh masyarakat berbau, berasa dan berwarna. Pengamatan secara langsung air yang keluar dari kran terlihat jernih, tapi beberapa jam setelah didiamkan terdapat endapan berwarna kuning kecoklatan, berbau besi, Untuk rumah tangga, lantai, dinding dan bak pada kamar mandi berwarna kecoklatan dan kehitaman karena terkena air secara terus menerus.

Gambaran ini menunjukkan akan terjadi di Manado khususnya di Kelurahan Malendeng, sehingga peneliti ingin meneliti hubungan kedalaman sumur bor dengan kadar Besi $(\mathrm{Fe})$ dan Mangan (Mn).

ada di Kelurahan Malendeng Kecamatan Paal 2 Manado. Standar kualitas air bersih menurut Permenkes RI Nomor 416/Menkes/PER/IX/1990 tentang Syarat-syarat dan Pengawasan Kualitas Air, Parameter Kimia untuk Besi (Fe) 1,0 mg/L. Mangan (Mn) 0,5 mg/L. Pengujian dilakukan di Balai Laboratorium Kesehatan Provinsi Sulawesi Utara.

\section{Hasil}

\section{Analisis Univariat}

Kedalaman Sumur Bor

Tabel 1. Distribusi Kedalaman Sumur Bor, Kadar Besi (Fe) dan Mangan (Mn) yang tidak memenuhi syarat di Kelurahan Malendeng Kecamatan Paal 2 Kota Manado.

\begin{tabular}{|c|c|c|c|c|c|c|c|c|c|c|c|c|}
\hline \multirow{2}{*}{$\begin{array}{c}\text { Kedalam Suumur } \\
\text { Bor }\end{array}$} & \multirow{2}{*}{$\mathrm{F}$} & \multirow{2}{*}{$\%$} & \multicolumn{4}{|c|}{ Besi (Fe) } & \multicolumn{4}{|c|}{ Mangan (Mn) } & \multicolumn{2}{|c|}{ Total } \\
\hline & & & MS & $\%$ & TMS & $\%$ & MS & $\%$ & TMS & $\%$ & $\mathrm{~N}$ & $\%$ \\
\hline Dangkal $(<20 \mathrm{~m})$ & 12 & 36 & 12 & 100 & 0 & 0 & 6 & 50 & 6 & 50 & 12 & 100 \\
\hline $\operatorname{Dalam}(>20 \mathrm{~m})$ & 21 & 64 & 20 & 95 & 1 & 5 & 14 & 67 & 7 & 33 & 21 & 100 \\
\hline Total & 33 & 100 & 32 & 97 & 1 & 3 & 13 & 61 & 13 & 39 & 33 & 100 \\
\hline
\end{tabular}

Tabel 1. Menunjukkan bahwa dari hasil observasi terhadap 33 sumur bor yang ada di Kelurahan Malendeng Kecamatan Paal 2 Manado dengan kategori sumur dangkal ( $<20$ meter) ada 12 sumur bor (36\%), dan sumur dalam ( > 20 meter) ada 21 sumur bor (64\%). Kadar Besi (Fe) yang tidak memenuhi syarat ada $1(3 \%)$ dan Mangan (Mn) yang tidak memenuhi syarat ada $13(39 \%)$.

\section{Analisis Bivariat}

Untuk menguji hubungan terhadap dua variable yang diduga berhubungan antara variable terikat (dependent) dengan variable bebas (independent) dengan uji Chi-
square.Adapun hasil Analisa bivariat yang diperoleh dalam penelitian ini adalah sebagai berikut: 
a. Hubungan Kedalaman Sumur Bor dengan Kadar Besi $(\mathrm{Fe})$ di Kelurahan Malendeng Kecamatan Paal 2 Kota Manado.

Tabel 2. Hubungan Kedalaman Sumur Bor dengan Kadar Besi (Fe) di Kelurahan Malendeng Kecamatan Paal 2 Kota Manado.

\begin{tabular}{|c|c|c|c|c|c|c|c|}
\hline \multirow{2}{*}{ Kedalam Suumur Bor } & \multicolumn{4}{|c|}{ Besi $(\mathrm{Fe})$} & \multicolumn{2}{|c|}{ Total } & \multirow{2}{*}{$p$} \\
\hline & MS & $\%$ & TMS & $\%$ & $\mathrm{~N}$ & $\%$ & \\
\hline Dangkal $(<20$ meter $)$ & 12 & 100 & 0 & 0 & 12 & 100 & \\
\hline Dalam (> 20 meter) & 20 & 95 & 1 & 5 & 21 & 100 & 1,000 \\
\hline Jumlah & 32 & 97 & 1 & 3 & 33 & 100 & \\
\hline
\end{tabular}

Tabel 2. Menunjukkan bahwa hasil uji statistik dengan menggunakan Chi-Square nilai $p$ value $1>0,05$ maka Ho diterima artinya tidak terdapat hubungan yang bermakna antara kedalaman sumur bor dengan kadar Besi (Fe), di Kelurahan Malendeng Kecamatan Paal 2 Manado.

b. Hubungan Kedalaman Sumur Bor dengan Mangan (Mn) di Kelurahan Malendeng Kecamatan Paal 2 Kota Manado.

Tabel 3. Hubungan Kedalaman Sumur Bor dengan Kandungan Mangan (Mn) di Kelurahan Malendeng Kecamatan Paal 2 Manado.

\begin{tabular}{|c|c|c|c|c|c|c|c|}
\hline \multirow{2}{*}{ Kedalam Suumur Bor } & \multicolumn{4}{|c|}{ Mangan (Mn) } & \multicolumn{2}{|c|}{ Total } & \multirow{2}{*}{$p$} \\
\hline & MS & $\%$ & TMS & $\%$ & $\mathrm{~N}$ & $\%$ & \\
\hline Dangkal $(<20$ meter $)$ & 6 & 50 & 6 & 50 & 12 & 100 & \\
\hline Dalam (> 20 meter) & 14 & 67 & 7 & 33 & 21 & 100 & 0,465 \\
\hline Jumlah & 13 & 61 & 13 & 39 & 33 & 100 & \\
\hline
\end{tabular}

Tabel 3. Menunjukkan bahwa hasil uji statistik dengan menggunakan Chi-Square nilai $p$ value 0,465 > 0,05 maka Ho diterima artinya tidak ada hubungan yang bermakna antara

\section{Pembahasan}

Air merupakan kebutuhan pokok yang dibutuhkan manusia untuk berbagai keperluan baik domestik maupun non domestik. Untuk mendapatkan air bersih, masyarakat bisa mendapatkan air dari mengambil air tanah salah satunya dengan membuat sumur bor dengan bantuan alat mesin bor untuk mencapai kedalaman sumur sampai mendapatkan sumber air yang diinginkan, dimana kedalaman sumur bor adalah jarak dari permukaan sampai ke dasar sumur, untuk memenuhi syarat kesehatan sebaiknya dilakukan pemeriksaan Laboratorium, karna tidak semua air kedalaman sumur bor dengan kadar Mangan (Mn), di Kelurahan Malendeng Kecamatan Paal 2 Manado.

tanah yang dapat dikonsumsi memenuhi standard kesehatan.

Hasil observasi yang dilakukan di lapangan maka dapat diketahui bahwa kedalaman sumur bor dengan kategori sumur dangkal $(<20 \mathrm{~m})$ ada $36 \%$, sumur dalam (>20 m ) ada $64 \%$ hal ini menunjukkan bahwa kedalaman sumur bor yang ada di Kelurahan Malendeng Kecamatan Paal 2 Manado pada sebagian besar sudah termasuk dalam kategori sumur dalam (> $20 \mathrm{~m}$ ) dimana sumur dalam mempunyai kualitas air lebih baik dari pada sumur dangkal, beberapa faktor yang memungkinkan banyaknya sumur dalam di Kelurahan Malendeng dikarenakan masyarakat 
berpendapat bahwa semakin dalam sumur bor maka semakin baik pula kualitas air yang didapat.

Sesuai hasil Laboratorium bahwa kadar besi (Fe) tidak memenuhi syarat ada satu sumur bor di Lingkungan IV dengan hasil $1,79 \mathrm{mg} / \mathrm{L}$, berada pada kedalaman 36 meter masuk dalam kategori sumur dalam (> $20 \mathrm{~m}$ ) sedangkan yang memenuhi syarat ada dalam kategori dangkal $(<20 \mathrm{~m})$ dengan tingginya kadar besi $(\mathrm{Fe})$ pada sumur bor dengan kedalaman 36 meter diduga pada lapisan tanah ada pelapukan bahan kimia tanah yang akan membentuk kadar besi (Fe) dan Mangan (Mn).

Menurut Mujianto, (2015) antara kandungan besi $(\mathrm{Fe})$ dalam air sumur, dimana semakin dalam galian sumur semakin tinggi kandungan $\mathrm{Fe}$ dalam air, kadar Fe yang tinggi sebagian besar berasal dari sumur yang mempunyai kedalaman diatas 30 meter.

Penelitian yang dilakukan oleh Mutiara pada air sumur bor di Kelurahan Malendeng pada tahun 2014 bahwa sampel air sumur bor yang diperiksa kadar Besi $(\mathrm{Fe})$ semua memenuhi syarat dengan rata-rata yaitu $0,03 \mathrm{mg} / \mathrm{l}$, dengan pertimbangan bahwa sumur bor yang diteliti termasuk dalam tipe air sumur dalam dengan kedalaman 15 meter

Berdasarkan uji Chi-Square diperoleh nilai $p$ value $1>0,05$ maka Ho diterima berarti tidak terdapat hubungan yang bermakna antara kedalaman sumur bor dengan kadar besi $(\mathrm{Fe})$ di Kelurahan Malendeng Kecamatan Paal 2 Manado).

Perbedaan hasil penelitian hubungan kedalaman sumur bor dengan kadar besi (Fe) antara satu peneliti dengan peneliti lainnya dapat terjadi karena beberapa faktor diantaranya tinggi rendahnya kandungan besi $(\mathrm{Fe})$ sangat dipengaruhi oleh kondisi struktur tanah, dan pada setiap wilayah akan memiliki perbedaan geografis, besi (Fe) merupakan salah satu unsur kimia yang dapat ditemui hampir pada setiap tempat di bumi, pada semua lapisan geologis dan semua badan air, (Herdiana, 2015).

Kandungan unsur kimia dalam air sangat tergantung pada formasi geologi tempat air itu, pemupukan besi $(\mathrm{Fe})$ di alam dapat menyebabkan perubahan iklim pada skala geologi, dimana air hujan yang turun jatuh ke tanah dan mengalami infiltrasi masuk ke dalam tanah yang mengandung $\mathrm{FeO}$ akan bereaksi dengan $\mathrm{H}_{2} \mathrm{O}$ dan $\mathrm{CO}_{2}$ dalam tanah dan membentuk $\mathrm{Fe}\left(\mathrm{HCO}_{3}\right)_{2}$ dimana semakin dalam air yang meresap ke dalam tanah semakin tinggi juga kelarutan besi karbonat dalam air tersebut, pada umumnya kandungan Besi $(\mathrm{Fe})$ berasal dari daerah di mana lapisan humusnya (top soil) agak tebal. Aliran air tanah merupakan perantara goelogi yang memberikan pengaruh berada dan formasi geologi tempat dilaluinya air, apabila selama perjalanannya air melalui suatu batuan yang mengandung besi, maka secara otomatis air akan mengandung besi, demikian juga untuk unsur-unsur yang lainnya.

Besar kecilnya material terlarut tergantung pada lamanya air kontak dengan batuan. Semakin lama air kontak dengan batuan semakin tinggi unsur-unsur yang terlarut di dalamnya. Pada air permukaan jarang ditemui kadar besi $(\mathrm{Fe})$ melebihi $1 \mathrm{mg} / \mathrm{l}$, tetapi di dalam air tanah kadar Fe dapat jauh lebih tinggi. Konsentrasi (Fe) yang tinggi dapat dirasakan dan dapat menodai kain serta perkakas dapur, dimana rasa dan bau logam yang amis pada air, disebabkan karena bakteri mengalami degradasi, besi (Fe) dalam konsentrasi yang lebih besar, akan memberikan suatu rasa pada air yang mengambarkan rasa metalik, menimbulkan warna kecoklat-coklatan pada pakaian putih, meninggalkan noda pada bak-bak kamar mandi dan peralatan lainnya (noda kecoklatan disebabkan oleh besi), dapat mengakibatkan penyempitan atau penyumbatan pada pipa dan endapan logam ini juga yang dapat memberikan masalah pada sistem penyediaan air secara individu (sumur).

Sesuai wawancara dengan keluarga yang menggunakan air sumur bor dengan kadar besi $(\mathrm{Fe})$ yang tidak memenuhi syarat bahwa air tersebut tidak dikonsumsi, melainkan dipergunakan mencuci baju, mandi dan mencuci perabot rumahtangga lainnya, dikarenakan keluarga sudah melihat secara fisik kondisi air yaitu berwarna, berbau, dan berasa.

Mangan (Mn) merupakan salah satu logam yang banyak dijumpai di kulit bumi dan sering terdapat bersama besi $(\mathrm{Fe})$, mangan terlarut dalam air tanah dan air permukaan yang miskin oksigen sehingga kadar mangan dalam air mencapai milligram /liter. Dalam jumlah tertentu dengan pemajanan oksigen, mangan bisa membentuk oksida yang tidak larut dan menghasilkan endapan sehingga menimbulkan masalah berupa penampilan fisik air yang mengganggu. Meskipun air tanah dan air permukaan secara alamiah mengandung mangan namun tambahan kosentrasi mangan dapat terjadi akibat adanya leachate 
(cairan lindi ) adalah cairan yang mengandung zat terlarut dan tesuspensi yang sangat halus sebagai hasil penguraian oleh mikroba.

Hasil pemeriksaan Laboratorium pada air sumur bor dengan kadar mangan (Mn) yang memenuhi syarat $61 \%$ dan tidak memenuhi syarat ada $39 \%$, yang tidak memenuhi syarat berjumlah 13 sumur bor, sumur bor $<20$ meter ada 6 sumur bor, dan untuk sumur $>20$ meter ada 7 sumur bor dan yang memenuhi syarat ada 20 sumur bor, untuk air sumur bor yang kadar Mangan (Mn) tinggi diduga pada lapisan tanah ada pelapukan bahan kimia tanah yang akan membentuk kadar besi (Fe) dan Mangan (Mn).

Berdasarkan uji Chi-Square diperoleh nilai $p$ value 0,465 > 0,05 maka Ho diterima berarti tidak terdapat hubungan yang bermakna antara kedalaman sumur bor dengan kadar mangan (Mn) di Kelurahan Malendeng Kecamatan Paal 2 Manado.

Penelitian yang dilakukan oleh Mutiara pada air sumur bor di Kelurahan Malendeng pada tahun 2014 bahwa sampel air sumur bor yang diperiksa kadar mangan (Mn) semua memenuhi syarat dengan rata-rata yaitu $0,03 \mathrm{mg} / \mathrm{l}$, dengan pertimbangan bahwa sumur bor yang diteliti termasuk dalam tipe air sumur dalam dengan kedalaman 15 meter.

Menurut Fajar, (2016) Sumur dangkal $(<20$ $\mathrm{m})$ untuk di daerah perkotaan yang tingkat polusi tanahnya tinggi biasanya kualitas airnya sangat buruk yaitu airnya kuning, kecoklatan, dan berbau, dikarenakan air berasal dari rembesan tanah sekitar yang berbatasan langsung dengan tanah terpolusi.

Berdasarkan wawancara dengan keluarga yang menggunakan air sumur bor dengan kadar mangan $(\mathrm{Mn})$ tidak memenuhi syarat bahwa air tersebut ada yang dikonsumsi, baik itu digunakan untuk masak, minum, mencuci baju, mandi dan mencuci perabot rumahtangga lainnya, hal ini terjadi dikarenakan masyarakat dalam kondisi tidak mengetahui kualitas air yang ada dan air tersebut merupakan sumber air bersih alternatir yang digunakan oleh masyarakat. Dampak kesehatan masyarakat bisa diprognosis jika masyarakat kelompok tersebut terus mengkonsumsi air bersih dengan kadar mangan (Mn) melebihi kadar yang ditentukan, (Suprayudi 2015).

Mangan merupakan salah satu dari tiga elemen penting namun beracun yang berarti bahwa unsur ini diperlukan bagi manusia untuk bertahan hidup, tetapi juga beracun ketika kosentrasi terlalu tinggi hadir dalam tubuh manusia, terutama di saluran pernapasan dan di otak. Gejala keracunan mangan adalah halusinasi, pelupa dan kerusakan saraf. Mangan juga dapat menyebabkan parkinson, emboli paru-paru dan bronkitis. Ketika orangorang yang terkena mangan untuk jangka waktu lama mereka menjadi impoten. Suatu sindrom yang disebabkan oleh mangan memiliki gejala seperti skizofrenia, kebodohan, lemah otot, sakit kepala dan insomnia. Kekurangan mangan juga dapat menyebabkan efek kesehatan diantaranya kegemukan, glukosa intoleransi, pembekuan darah, masalah kulit, menurunkan kadar kolesterol, ganguan skeleton, kelahiran cacat, perubahan warna rambut, gejala Neurological, (Suprayudi, 2015).

Senyawa mangan secara alami ada dalam lingkungan sebagai padatan di dalam tanah dan partikel kecil di dalam air. Partikel mangan di udara yang hadir dalam partikel debu. Biasanya ini menetap ke bumi dalam waktu beberapa hari.

Sesuai dengan Permenkes RI No.416/Menkes/PER/IX/1990 bahwa kualitas air harus memenuhi syarat kesehatan yang meliputi persyaratan mikrobiologi, fisika, kimia dan radioaktif Untuk mencegah penurunan kualitas dan penggunaan air yang dapat mengganggu dan membahayakan kesehatan, serta meningkatkan kualitas air.

Menurut Makhmud dan Notodarmojo (2010), penurunan kualitas air diantaranya diakibatkan oleh kandungan besi dan mangan yang sudah ada pada tanah karena lapisan-lapisan tanah yang dilewati air mengandung unsur kimia tertentu salah satunya adalah persenyawaan besi $(\mathrm{Fe})$ dan mangan (Mn).

Tingginya Kadar Besi (Fe) dan Mangan (Mn) pada air sumur bor di Kelurahan malendeng Kecamatan Paal 2 Manado dengan kedalaman sumur bor $>20$ meter diduga pada lapisan tanah yang dilewati air adanya pelapukan bahan kimia tanah yang akan membentuk senyawa Besi (Fe) dan Mangan (Mn), untuk itu dalam pengeboran air harus memperhatikan formasi lapisan tanah, agar mendapat kualitas air yang baik. 


\section{Kesimpulan}

1. Kedalaman Sumur Bor yang ada di Kelurahan Malendeng Kecamatan Paal 2 Manado yaitu sumur $<20$ meter ada 12 sumur bor $(36 \%)$, dan sumur $>20$ meter ada 21 sumur bor $(64 \%)$.

2. Pada air sumur bor di Kelurahan Malendeng Kecamatan Paal 2 Manado yaitu untuk kadar Besi $(\mathrm{Fe})$ yang tidak memenuhi syarat $3 \%$, untuk Mangan (Mn) yang tidak memenuhi syarat $39 \%$.

3. Tidak ada hubungan bermakna antara kedalaman sumur bor dengan kadar besi $(\mathrm{Fe})$ dan mangan (Mn) di Kelurahan Malendeng Kecamatan Paal 2 Manado.

\section{Saran}

1. Pemerintah Kelurahan Malendeng hendaknya memperhatikan sumber air bersih alternatif agar masyarakat dapat memperoleh air yang memenuhi syarat kesehatan.

2. Pemerintah Kelurahan Malendeng hendaknya melakukan upaya promosi kesehatan melalui puskesmas setempat kepada masyarakat terkait risiko kesehatan masyarakat apabila masyarakat mengkonsumsi air sumur gali dengan kadar Mn melebihi ambang batas yang ditentukan.

3. Pada masyarakat yang mempunyai sumur bor dimana kadar besi $(\mathrm{Fe})$ dan mangan $(\mathrm{Mn})$ tidak memenuhi syarat diharapkan agar masyarakat lebih memperhatikan kondisi kualitas air yang memenuhi syarat kesehatan.

\section{Daftar Pustaka}

Fajar, (2016). Kedalaman sumur bor yang baik https://jualfilterpenyaringair/kedalamansumur-bor-yang-baik. (di akses April 2017).

Herdiana, A (2015) Kandungan Besi Dalam Air www. informasi kesling. blogspot.com (diakses Desember 2017).

Makhmud, N, dan Notodarmojo (2010), Penyisihan Besi-Mangan, Kekeruhan Dan Warna Menggunakan Saringan Pasir Lambat Dua Tingkat Pada Kondisi Aliran Tak Jenuh. Jurnal Teknik Lingkungan. Institut Teknologi Bandung.
Mujianto,B, Purwanti, A, dan Rismini S. (2015). Kandungan Besi Air Sumur Di Perumahan Huma Akasia, Jatiwara Bekasi. Jurnal Ilmu dan Teknologi Kesehatan, Vol 2, Nomor 2. Maret 2015.

Munfiah, S., Nurjazuli., \& Setiani, O. (2013). Kualitas Fisik dan Kimia Air Sumur Gali dan Sumur Bor. Di Wilayah Kerja Puskesmas Guntur II. Kabupaten Demak. Jurnal Kesehatan Lingkungan Indonesia Vol. 12 No. 2 / Oktober 2013.

Mutiara, A, Ismail (2014). Kadar Besi (Fe) dan Mangan (Mn) pada Sumur Bor di Kelurahan Malendeng. Kecamatan Paal 2. KTI Penelitian Jurusan Kesehatan lingkungan Manado.

Permenkes RI Nomor 416/Menkes/PER/IX/1990 Tentang Syarat-syarat dan Pengawasan Kualitas Air.

Permendagri Nomor 23 Tahun 2006 Tentang Pedoman Teknis dan Tata Cara Pengaturan Tarif Air Minum Pada Perusahaan Daerah Air Minum.

Permenkes RI Nomor 32 Tahun 2017 tentang Standar Baku Mutu Kesehatan lingkungan dan Persyaratan Kesehatan Air untuk Keperluan Higiene Sanitasi, kolam Renang, Solus Per Aqua dan Permandian Umum.

Riskesdas, (2013). Riset Kesehatan Dasar. Badan Penelitian dan Pengembangan Kesehatan. Kementrian Kesehatan RI.

Setiyono, A (2014). Studi Kadar Mangan (Mn) Pada Air Sumur Gali. Di Desa Karangnunggal. Kecamatan Karangnunggak. Kabupaten Tasikmalaya. Jurnal Kesehatan Komunitas Indonesia Vol. 10. No. 1 Maret 2014.

Suprayudi,M dan Abdul M, F. (2015). Analisa Kadar Mangan (Mn) Pada air Sumur, Di Daerah Cipto Mulyo Kecamatan Sukun Kota Malang. Jurnal Healthy Science 26 Juni 2015.

Sari, W.K., dan Nieke, K. (2014). Study penurunan Besi ( $\mathrm{Fe}$ ) dan Mangan (Mn) dengan menggunakan Cascade Aerator dan Rapid Sand Filter Pada Air Sumur Gali. Skripsi Jurusan Teknik Lingkungan. ITS Surabaya. 